\title{
Modernización del estado y de la administración pública en Colombia, la política pública de rendición de cuentas social y el fortalecimiento de la democracia
}

\section{Modernization of the state and public administration in Colombia, public policy of social accountability and the strength of democracy}

\author{
JOSÉ NIEVES-LÓPEZ \\ Abogado, Especialista en Derecho Administrativo y en Contratación Estatal. \\ Universidad Externado de Colombia. Miembro del-Grupo de Investigación en Derecho y Ciencia Política-GIDECP. \\ Abogados asociados \\ josegabrielnieves@hotmail.com \\ Recibido: Noviembre 30 de 2012 \\ Aceptado: Abril 15 de 2013
}

\begin{abstract}
En una democracia participativa en la que se articulan las tensiones y las relaciones de poder entre el gobernante y los gobernados, el acceso a la información y el derecho de los ciudadanos a participar y ejercer control social sobre el desempeño y gestión de las entidades públicas, constituyen instrumentos indispensables para el mejoramiento de la transparencia dentro del Estado, reafirmar el Contrato Social y legitimar el poder público. El presente artículo de reflexión pretende hacer un análisis desde las estructuras y acciones conformadas por el Estado para la implementación de la Política Pública de Rendición de Cuentas Social y sus implicaciones en el fortalecimiento de la democracia colombiana.

Palabras Clave: Rendición de Cuentas Social, Información Pública, Sociedad Civil, Transparencia, Democracia.

ABSTRACT

In a participative democracy, where there are tensions and the relationships of power that are articulated among the ruler and those governed, the access to the information and the right of the citizens to participate and exercise social control on the acting and the administration of the public entity constitute indispensable instruments for the improvement of transparency inside the State, to reaffirm the Social Contract and to legitimate the public power. This paper seeks to make an analysis from the structures and actions conformed by the State for the Public Politics of Social Accountability implementation and its implications in the invigoration of the Colombian democracy.

Key Words: Social Accountability, Public Information, Civil Society, Transparency, Democracy
\end{abstract}

RESUMEN 


\section{Introducción}

El desgaste de los gobiernos autoritarios de corte dictatorial que detentaron el poder en América Latina hasta finales del siglo $X X^{1}$ trajo como consecuencia un período de transición hacia un sistema democrático que permitió la consolidación de espacios de participación ciudadana y de organizaciones sociales.

La construcción de canales de diálogo entre los distintos actores de la sociedad civil y el gobierno constituyen una visión moderna de la democracia y son en gran medida una herramienta fundamental para influir en la formulación, seguimiento y evaluación de las políticas públicas orientadas al mejoramiento de la Administración Pública y la modernización del Estado.

En este orden de ideas, García-Iragorri (2008) citando a Schimitter y Karl (1996, p 52) entiende la democracia como un concepto que va más allá de las simples elecciones periódicas y justas, pues considera también el espacio que los ciudadanos deben tener para influir en la política pública por medio de los grupos, asociaciones, movimientos sociales y organizaciones similares (p. 33).

Los altos índices de corrupción, las prácticas clientelistas, los bajos índices de desempeño en la administración pública y, en consecuencia, la pérdida de legitimidad y confianza de los ciudadanos en las instituciones, originan las reclamaciones de una sociedad civil organizada sobre las actuaciones del Estado y mantiene la preocupación de los gobiernos por implementar instrumentos eficaces que les permitan una apropiada rendición de cuentas, dando así visibilidad a sus acciones.

De acuerdo a lo anterior, la importancia de la rendición de cuentas radica en su contribución hacia el fortalecimiento de la democracia y la construcción de un Estado justo, eficiente y eficaz, capaz de gestionar medidas que propicien el desarrollo de la sociedad en cumplimiento de los principios de transparencia y publicidad en la Administración Pública.

El presente artículo pretende desde una perspectiva jurídico-política el análisis de la Política Pública de Rendición Social de Cuentas en Colombia. En un primer momento se abordarán las diferentes definiciones sobre rendición de cuentas elaboradas por algunos autores, luego se describirán los tipos de rendición de cuentas existentes, para posteriormente tratar el tema de la participación ciuda-

Ver los casos de las dictaduras militares en Argentina (1976-1983), Brasil (1964-1985), Chile (1973-1990), Uruguay (1973-1985), Panamá (1968-1989), Guatemala (1954-1986), entre otros. dana y el papel que juega la sociedad civil en la gestión pública dentro del Estado. Finalmente se analizará la adopción de la Política Pública de Rendición de Cuentas Social en Colombia.

\section{La Rendición de cuentas: aproximación a su definición}

En una democracia moderna no solo es necesario contar con un Estado eficiente, eficaz y justo para determinar su calidad democrática y gobernabilidad, pues es necesario que existan mecanismos que vigilen y controlen las actuaciones estatales; razón por lo cual el concepto de rendición de cuentas cobra relevancia en nuestros tiempos.

La rendición de cuentas o accountability ${ }^{2}$, es entendida como la obligación de un actor, de informar y explicar sus actuaciones a otros que tienen el derecho a exigirla, dado a que existe entre éstos una relación de poder, lo que permite imponer sanciones ante un comportamiento inadecuado o premiar un comportamiento destacado.

En términos políticos y de estructura del Estado, la rendición de cuentas es el conjunto de estructuras (conjunto de normas jurídicas y de instituciones responsables de informar, explicar y enfrentar premios o sanciones por sus actos), prácticas (acciones concretas adelantadas por las instituciones, los servidores públicos, la sociedad civil y la ciudadanía en general) y resultados (productos y consecuencias generadas a partir de las prácticas) mediante los cuales, las organizaciones estatales y los servidores públicos informan, explican y enfrentan premios o sanciones por sus actos a otras instituciones públicas, organismos internacionales y a los ciudadanos y la sociedad civil, quienes tienen el derecho a recibir información y explicaciones y la capacidad de imponer sanciones o premios, al menos simbólicos. (Schedler, 2004; Grant y Keohane, 2005 citados por el Departamento Nacional de Planeación, 2010).

De la anterior definición se rescatan tres componentes básicos que conforman el concepto de rendición de cuentas: La información, el diálogo y el incentivo. Para Grant y Keohane (2005) la información se refiere a la disponibilidad, exposición y difusión de los datos, estadísticas, documentos, informes, entre otros sobre las funciones a cargo de la institución o servidor público, desde el momento de la planeación hasta las fases de control y evaluación de las políticas. El diálogo o explicación se encuentra en la sustentación de las acciones, la presentación de diagnósticos e interpretaciones, la exposición de criterios utiliza-

\footnotetext{
2 Algunos autores hablan de control social como vigilancia social (Insunza y Olvera, 2006).
} 
dos para tomar decisiones, lo que implica la existencia de un diálogo y la posibilidad de influir sobre otros actores sobre las decisiones a tomar. Finalmente, los incentivos o estímulos son mecanismos de corrección de las acciones, de estímulo por su adecuado cumplimiento o castigo o reproche ${ }^{3}$ por el mal desempeño.

Por eso la posibilidad de escrutinio público sobre los procesos de formación de las decisiones públicas y acerca de sus resultados puede ser tanto o más importante que la creación de órganos de control social, ya que la sola institución del derecho a la información y de su exigibilidad se convierten en recursos de influencia de la sociedad sobre el Estado y, en general, sobre asuntos públicos. (Cunill, 2006).

A continuación se expone una ilustración que recrea la dinámica existente en cuanto a los componentes que integran los procesos de rendición de cuentas:

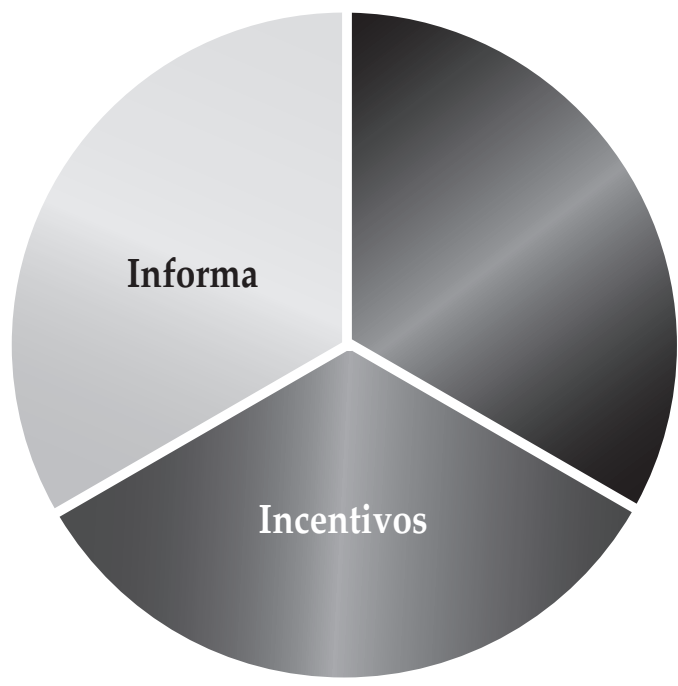

Fuente: Departamento Nacional de Planeación - Dirección de Evaluación de Políticas Públicas (2010)

Ilustración 1. Componentes de la Rendición de Cuentas

Ahora bien, la rendición de cuentas no solo implica una relación bidireccional entre las informaciones y explicaciones solicitadas por los ciudadanos y diversos actores de la sociedad civil al gobernante y el deber de éste de rendir oportunamente y salvaguardar el principio de publicidad de las actuaciones públicas, sino que por otra parte, implica la obligación de generar, organizar, difun-

3 Ackerman (2003) y O'Donnell (2007) definen la desaprobación de las actuaciones estatales como objeto de castigos "simbólicos". dir y facilitar el acceso a una información veraz y confiable por parte de la Administración.

Con la rendición de cuentas se trata de favorecer una mayor responsabilidad entre todas las partes mediante la mejora de los mecanismos de consulta y de diálogo para reforzar la legitimidad de las políticas públicas. Los instrumentos principalmente son la provisión de información sobre las políticas y las acciones de las diferente instituciones y organizaciones y la creación y el estímulo de oportunidades para la consulta y la participación activa de los ciudadanos en la formación y en la elaboración de las políticas públicas (Nonell, 2006).

Lo anterior denota que la democracia dentro de un Estado moderno se revela, de hecho, como una manera de que las políticas públicas se pongan al servicio del ciudadano. Los lazos de confianza mutua, un sistema de reglas que permita a las partes determinar que compromisos pueden cumplir, son elementos necesarios para que una sociedad civil autónoma y sólida pueda activar los controles y demandas frente al déficit institucional que aqueja a la democracia.

La participación ciudadana aparece como un elemento clave para asegurar la sostenibilidad en la implementación de las políticas públicas y contribuir a legitimar las acciones del Estado, puesto que los ciudadanos participan activamente en la gestión pública y generan un diálogo con las instituciones. Evidentemente ello significa la creación de incentivos apropiados para que las acciones del Estado ${ }^{4}$ se manejen de manera transparente y se busque una mayor eficiencia en el diseño y operatividad de sus acciones.

Por lo expresado, en la teoría de la democracia se reconoce cada vez con mayor relevancia el papel que juega la rendición de cuentas como un elemento esencial en la modernización del Estado, la ampliación de los espacios públicos, la consolidación de la democracia y la conformación de un estatuto para la ciudadanía más incluyente. En este sentido, la rendición de cuentas ayuda a establecer los cimientos sociales de la democracia.

\footnotetext{
"Son fines esenciales del Estado: servir a la comunidad, promover la prosperidad general y garantizar la efectividad de los principios, derechos y deberes consagrados en la Constitución; facilitar la participación de todos en las decisiones que los afectan y en la vida económica, política, administrativa y cultural de la Nación; defender la independencia nacional, mantener la integridad territorial y asegurar la convivencia pacífica y la vigencia de un orden justo. Las autoridades de la República están instituidas para proteger a todas las personas residentes en Colombia, en su vida, honra, bienes, creencias, y demás derechos y libertades, y para asegurar el cumplimiento de los deberes sociales del Estado y de los particulares" (Constitución Política de Colombia,1991: art. 2º).
} 


\section{Tipología de la rendición de cuentas}

O'Donnell, Smulovitz, Peruzzotti, Ackerman, entre otros, se han ocupado de estudiar a profundidad el concepto de rendición de cuentas o accountability y, han determinado una clasificación de ésta conforme a factores espaciales, temporales o institucionales, que para el caso de este trabajo resultan más que pertinentes mencionar y describir.

Gutiérrez-Saxe (2006), por ejemplo sostiene en que en una democracia de alta calidad están desarrolladas la rendición de cuentas política, legal y administrativa. La primera se refiere a los mecanismos ciudadanos para velar por el cumplimiento de las ofertas electorales, el buen gobierno y la gobernabilidad. Se trata de tomar la palabra a quienes solicitan los votos de la ciudadanía y sancionar severamente el engaño. La segunda contempla los mecanismos para el control de la legalidad y justicia. No basta la existencia de un Estado de Derecho sino que el poder político debe estar sujeto a él. Ninguna institución o persona está por encima de la ley, tanto en el ámbito público como en el privado. Además, la administración de justicia debe estar abierta al escrutinio público como un medio para contribuir a una justicia igual, pronta y cumplida para todas las personas. Por último, la rendición de cuentas administrativa se refiere a los mecanismos para el control y la evaluación para la eficacia y trato decente en la función pública.

Para Insunza y Olvera (2006) la rendición de cuentas debe clasificarse por eje temporal, así crean una clasificación en el cual determinan si es prospectiva, procesal o retrospectiva. La primera exige la presencia de grupos organizados de ciudadanos un cierto conocimiento que les permita plantear las necesidades en la forma apropiada y la existencia de instancias de diálogo y negociación con el gobierno que mientras más institucionalizadas estén puedan ser más eficientes y eficaces. La segunda tiene una mayor relación con la necesidad del conocimiento técnico y de un corpus profesional permanente que tenga capacidad de interacción y diálogo con los aparatos estatales. Finalmente la rendición de cuentas retrospectiva implica una mayor participación ciudadana pero además requiere mayor conocimiento técnico y claridad política, pues debe encargarse de evaluar y efectuar el balance público de la acción estatal.

No obstante a las anteriores clasificaciones, este trabajo adopta la clasificación efectuada inicialmente por O'Donnell sobre accountability horizontal y vertical, y acoge el concepto de accountability societal desarrollado por Smulovitz y Peruzzotti, pretendiendo desarrollar algunos conceptos plasmados en el Documento Conpes 3654 de 2010 o Política de Rendición de Cuentas Social presentado por el Departamento Nacional de Planeación.

\section{a. Rendición de cuentas horizontal ${ }^{5}$}

La existencia de agencias estatales que tienen autoridad legal y están fácticamente dispuestas y capacitadas (empowered) para emprender acciones que van desde el control rutinario hasta sanciones penales o incluso impeachment, en relación con actos u omisiones de otros agentes o agencias del estado que pueden, en principio o presuntamente, ser calificadas como ilícitos (O'Donnell, 2007). Se clasifica en rendición de cuentas de equilibrio y rendición de cuentas asignadas o de agencia, ejercida por entidades de mandato específico.

\section{Rendición de cuentas de equilibrio}

Este tipo de rendición de cuentas consiste en el conjunto de estructuras, prácticas y resultados mediante los cuales las ramas del poder público -ejecutivo, legislativo y judicial- se informan, explican y enfrentan premios o sanciones entre ellas mismas. Esta rendición de cuentas surge del diseño institucional de las repúblicas democráticas que busca la distribución del poder con el fin de evitar su concentración absoluta y por tanto su degeneración y abuso. Más que una estricta rendición de cuentas, se trata de la creación de normas y procedimientos que permitan a cada poder reaccionar y obtener los correctivos requeridos cuando otro de los poderes interfiera dentro de su ámbito de competencia. Sin embargo, dentro de ciertos contextos se establecen estructuras y prácticas que exigen la información e los actos entre los poderes, y se han definido mecanismos de sanción.

\section{Rendición de cuentas asignadas ${ }^{6}$}

La rendición de cuentas asignada, de agencia o por instituciones de mandato pretende corregir las deficiencias del balance de poderes. Se trata de órganos creados específicamente con la finalidad de controlar el desempeño y el comportamiento de las tres ramas del poder tradicionales. Estas agencias suelen tener autonomía y pueden solicitar información, verificar el cumplimiento de conductas, recibir y tramitar quejas sobre el comportamiento de las instituciones y sus servidores, y de aplicar sanciones en casos determinados Usualmente estos órganos se

Si bien el artículo 113 constitucional habla de la "colaboración armónica" entre las ramas del poder público, es en el artículo 114 ejusdem donde se observa con claridad el concepto e accountability horizontal plasmado en la Carta Política. "Corresponde al Congreso de la República reformar la Constitución, hacer las leyes y ejercer control político sobre el gobierno y la administración" (Negrillas y subrayado fuera de texto).

6 Al respecto el Ministerio Público y la Contraloría General de la Nación son los organismos de control que ejercen directamente el control disciplinario y fiscal preferente sobre el resto de entidades que integran las Ramas del Poder Público. 
enfocan en las conductas violatorias de normas, pero también pueden abordar la obtención de resultados. Tradicionalmente estos órganos de control se abordan asuntos disciplinarios, corrupción, derechos humanos, sociales, económicos, ambientales y culturales, fiscales y penales.

\section{b. Rendición de cuentas vertical ${ }^{7}$}

La rendición de cuentas vertical asume que existe una relación jerárquica entre los ciudadanos y los servidores públicos elegidos, en la cual los primeros delegan en los segundos unas tareas de representación. El supuesto fundamental de esta forma de rendición de cuentas está en el origen de la teoría de la democracia: la soberanía y el poder de una democracia residen en los ciudadanos y los gobernantes son representantes que deben responder antes éstos, quienes los eligen y son la fuente de su legitimidad (y también pueden revocarles el mandato o no reelegirlos a ellos a los partidos políticos que representen). La obligación de informar y explicar las acciones de los gobernantes y servidores públicos se desprende naturalmente de esta situación. Sin embargo, en la práctica el poder de sanción de los ciudadanos es limitado y algunas veces solamente simbólico y los representantes suelen tener más poder que estos. La rendición de cuentas vertical se divide en Rendición de Cuentas Electoral y Rendición de Cuentas Social.

\section{Rendición de cuentas electoral}

La rendición de cuentas electoral consiste en el conjunto de estructuras, prácticas y resultados mediante el cual los representantes electos informan, explican y enfrentan sanciones o premios por parte de sus electores, Mediante la votación de los electores escogen entre diferentes opciones según la información y las explicaciones planteadas por los candidatos. Esta rendición de cuentas se produce a intervalos según las fechas de realización de las elecciones, e implica la existencia de una reelección (inmediata o con un período intermedio) para que efectivamente se produzca una sanción o premio, de la existencia de un reducido y sólido número partidos políticos, que actúen de forma coherente y responsable frente a sus electores.

\section{Rendición de cuentas social}

La rendición de cuentas social es el conjunto de estructuras, prácticas y resultados mediante los cuales los fun-

El ejemplo más evidente de accountability vertical se expresa en el artículo 23 constitucional "Toda persona tiene derecho a presentar peticiones respetuosas a las autoridades por motivos de interés general o particular y a obtener pronta resolución. El legislador podrá reglamentar su ejercicio ante organizaciones privadas para garantizar los derechos fundamentales" cionarios y servidores públicos informan, explica y se enfrentan a sanciones o premios por parte de los diversos sujetos de la sociedad civil (ciudadanos, organizaciones sociales, grupos de interés, empresas, medios de comunicación, movimientos sociales). La rendición de cuentas social puede ser de tipo legal (control sobre el comportamiento y las obligaciones jurídicas de los servidores públicos), de desempeño (control y petición de cuentas sobre los resultados de las acciones del Estado) y política (control sobre la responsabilidad política del gobierno).

Los ciudadanos tienen derecho a pedir información y explicaciones de los gobernantes porque la soberanía reside en ellos como constituyentes primarios del poder público. En la práctica, las asimetrías de poder entre los dos tipos de actores generan una necesidad especial de fortalecer la capacidad de petición de cuentas de os ciudadanos y la obligación de rendir cuentas de los gobernantes. En cuanto a la sanción, en este caso los ciudadanos pueden imponer una censura moral o mostrar su desaprobación a través de los medios de comunicación o de manifestaciones simbólicas; acudir a las autoridades competentes para solicitar que se investigue o castigue un acto. (Ilustración 2).

\section{Rendición de cuentas diagonal ${ }^{8}$}

La rendición de cuentas diagonal combina la rendición de cuentas horizontal asignada con la rendición de cuentas vertical social. Es decir se trata de mecanismos o instancias en las cuales la sociedad civil se articula con los órganos de control para efectos de la información, la explicación y los premios o sanciones (Banco Mundial, 2004). Consiste en que os ciudadanos colaboran con los organismos de control en espacios ad hoc para ejercer control sobre un aspecto de la gestión pública, pero ha sido criticada porque implica en ocasiones que los ciudadanos se conviertan en cogestores y en esa medida pierdan la distancia necesaria para controlar y pedir cuentas como agentes externos al Estado.

\section{c. Rendición de cuentas interna}

En las instituciones públicas se establece un esquema de rendición de cuentas de los superiores a los servidores públicos subordinados, según la escala jerárquica. En particular, los servidores elegidos democráticamente deben

8 Para Isunza y Olvera (2006) son instituciones del Estado, que si bien están diseñadas y funcionan de tal forma que hunden sus raíces de manera explícita en la sociedad civil, a través de la presencia especialmente protegida de ciudadanos autónomos e independientes que no representan pero sí ejemplifican las cualidades de un ethos ciudadano. 


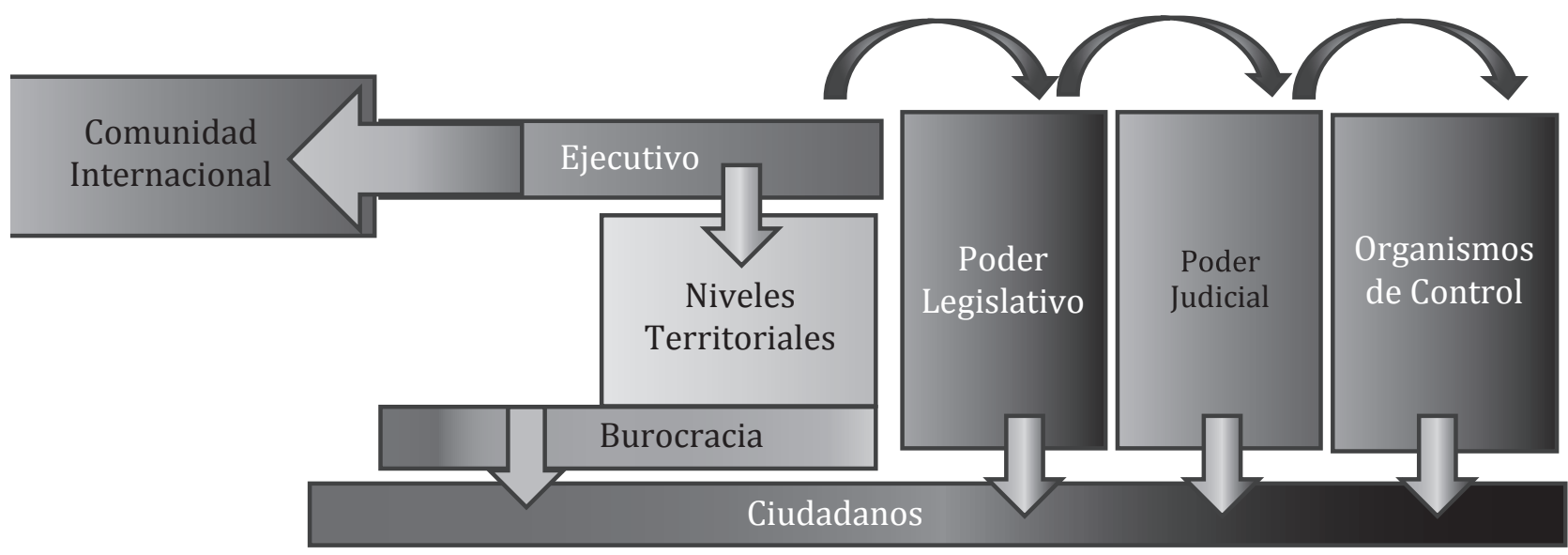

Fuente: Elaborado por el Departamento Nacional de Planeación - Dirección de Evaluación de Políticas Públicas (2010)

Ilustración 2. Esquema de rendición de cuentas en Colombia

pedir cuentas a los funcionarios y servidores públicos no elegidos, pues los primeros representan a los ciudadanos y deben a su vez dar cuentas por medio de la rendición de cuentas vertical. De este modo los funcionarios (nombrados o de carrera) y los servidores públicos en general deben informar y explicar sus actos y pueden exponerse a sanciones o premios de diversa naturaleza: laborales, incentivos económicos, sanciones disciplinarias. Los sistemas de control interno constituyen un soporte para este tipo de de rendición de cuentas.

Entre entidades públicas del poder ejecutivo se produce también la rendición de cuentas interna, dado que genera información, explicaciones y posibilidades de premios o sanciones.

Esta rendición de cuentas se puede dar desde los Ministerios hacia la Presidencia, de las entidades vinculadas y adscritas hacia los Ministerios cabeza de sector y de los Ministerios y entidades hacia entidades de planificación y presupuesto.

\section{d. Rendición de cuentas entre entidades territoriales}

Adicional a los anteriores tipos y debido a la existencia de diferentes niveles de gobierno, se genera también la rendición de cuentas entre ellos. Esta se podría considerar similar a la rendición de cuentas interna o a la horizontal, pero tiene diferencias con ambas, ya que las entidades territoriales (departamentos y municipios) tienen autonomía en cuanto a sus competencias, sus cabezas son elegidas por votación democrática (alcaldes y gobernadores), pero el nivel central del gobierno guarda cierta preeminencia frente a estas y tiene la capacidad de pedirles cuentas en algunas materias.
Por una parte, las entidades nacionales deben informar y explicar a las entidades territoriales sobre su gestión en los territorios específicos y se exponen a sanciones morales o políticas, en la medida en que las autoridades y las comunidades territoriales consideren que no se está adelantando una gestión adecuada. Por la otra, las entidades territoriales deben informar y explicar a entidades nacionales, sean del ejecutivo o de órganos de control, sobre su gestión y resultados y se exponen a sanciones de diferente naturaleza. El diseño constitucional que busca distribuir el poder y crea mecanismos de rendición de cuentas entre dichos poderes se aplica también a la división territorial del Estado, sea mediante la forma federal o centralizada.

\section{c. Rendición de cuentas externa}

En el contexto de la globalización y la integración internacional, ciertas competencias estatales comienzan a ser asumidas por organizaciones internacionales, los Estados adhieren a compromisos internacionales de diversa naturaleza y establecen acuerdos en los que se someten a mecanismos de rendición de cuentas hacia organismos externos. En materia de de desarrollo, por ejemplo los países firmantes adquirieron compromisos con metas del milenio en temas específicos, sobre los cuales deben generar información y explicaciones a la comunidad internacional, y pueden enfrentar premios o sanciones, desde morales hasta económicas, políticas e incluso militares.

Si bien este tipo de rendición de cuentas no está tradicionalmente incluido en las clasificaciones de la literatura especializada, se considera relevante pues cabe dentro de la definición que se ha planteado y tiene consecuencias para los Estados en los niveles de información, explicaciones y sanciones. 
Tabla 1. Tipos de rendición de cuentas en Colombia

\begin{tabular}{|l|l|l|}
\hline \multicolumn{2}{|c|}{ Rendición de Cuentas } & \multicolumn{1}{c|}{ Prácticas } \\
\hline \multirow{4}{*}{ El. Vertical } & $\begin{array}{l}\text { Reelección consecutiva (Congresistas, presidente, diputados, concejales) } \\
\text { Reelección no consecutiva (Alcaldes y Gobernadores) } \\
\text { Revocatoria del mandato }\end{array}$ \\
\cline { 2 - 3 } & Social & $\begin{array}{l}\text { Veedurías } \\
\text { Audiencias Públicas } \\
\text { Gobierno en Línea } \\
\text { Consejos Nacional y territoriales de Planeación } \\
\text { Consejos comunales }\end{array}$ \\
\hline ii. Horizontal & De equilibrio & $\begin{array}{l}\text { Separación y balance de poderes constitucional } \\
\text { Control político del Congreso } \\
\text { Nominación y nombramiento tripartito de altos cargos de organismos de control } \\
\text { Control constitucional }\end{array}$ \\
\hline iii. Diagonal & Asignada & $\begin{array}{l}\text { Organismos de control autónomos: Contraloría General de la Nación y Ministerio } \\
\text { Público }\end{array}$ \\
\hline \multirow{2}{*}{ iv. Interna } & Controles de gestión \\
\hline v. Entre niveles territoriales & $\begin{array}{l}\text { Acuerdos de gestión } \\
\text { Consejos de ministros }\end{array}$ \\
\hline \multirow{2}{*}{ vi. Externa } & Consejos comunales \\
\hline
\end{tabular}

Fuente: Elaborado por el Departamento Nacional de Planeación - Dirección de Evaluación de Políticas Públicas (2010)

Como se puede observar de las diferentes clasificaciones de rendición de cuentas que se muestran en la Tabla anterior, siempre se destacan los componentes de información, diálogo e incentivos y no su función no puede ser aislada, por el contrario, se deben complementar para que se cumplan los propósitos de transparencia y control de la gestión pública dentro del Estado.

Los tipos de rendición de cuentas anteriormente descritos no son ajenos al ordenamiento jurídico colombiano, a partir de la Constitución Política de 1991 se abrieron espacios para la participación del ciudadano como centro de la función pública y así como la consagración del derecho al control social a las entidades y organizaciones del Estado. Tal vez la rendición de cuentas horizontal tiene un mayor reconocimiento por parte de los ciudadanos, en virtud, que corresponde al Ministerio Público y a la Contraloría General de la Nación activarla ante las otras entidades del Estado, sin embargo, en la rendición de cuentas vertical social la que realmente tiene un mayor incidencia en un la generación de un diálogo fluido entre los actores de la sociedad civil y la Administración en Colombia.

\section{La tendición de cuentas en Colombia: esquemas de participación ciudadana, acceso a la información pública y transparencia}

Los procesos de rendición de cuentas permiten fortalecer la gestión integral ${ }^{9}$ dentro de las administraciones, involucrando necesariamente la participación ciudadana como el elemento que garantiza que el sistema en su conjunto esté constantemente orientado hacia la satisfacción de las demandas y expectativas de la sociedad civil. En este sentido, la rendición de cuentas permite reafirmar el

\footnotetext{
$9 \quad$ Entiéndase gestión integral como la articulación permanente de los procesos de planeación, acciones de gobierno y evaluación, con la cual la planeación deja de ser un proceso estático para convertirse en uno dinámico, continuamente retroalimentado. (Departamento Nacional de Planeación, 2004).
} 
derecho de la sociedad civil ${ }^{10}$ de exigir resultados de la gestión pública al gobierno.

El fortalecimiento de una democracia constitucional guarda estrecha relación con la garantía del derecho de todas las personas a acceder a los documentos públicos, salvo los casos que establezca la ley. Así, la publicidad de la información permite que las personas puedan controlar la gestión pública, en sus diversos órdenes: presupuestal, grado de avance en los objetivos planteados, planes del Estado para mejorar las condiciones de vida de la sociedad, entre otros. Al respecto, la Constitución Política de 1991 consagra la democracia participativa como uno de los principios fundamentales del Estado ${ }^{11}$ colombiano. De allí que, en consecuencia, en su artículo 74 establezca, como regla general, que las personas tienen derecho a acceder a los documentos públicos, y que únicamente por voluntad del legislador y de manera excepcional, algunos de aquellos estarán sometidos a reserva.

Para la Constitución Política la garantía más importante del adecuado funcionamiento del régimen constitucional está en la plena publicidad y transparencia de la gestión pública. Las decisiones o actuaciones de los servidores públicos que no se quieren mostrar son usualmente aquellas que no se pueden justificar. Y el uso secreto e injustificado del poder del Estado repugna al Estado de derecho y al adecuado funcionamiento de una sociedad democrática. En efecto, la transparencia y la publicidad de la información pública son dos condiciones necesarias para que las agencias del Estado se vean obligadas a explicar públicamente las decisiones adoptadas y el uso que le han dado al poder y a los recursos públicos; son la garantía más importante de la lucha contra la corrupción y del sometimiento de los servidores públicos a los fines y procedimientos que les impone el derecho; son la base sobre la cual se puede ejercer un verdadero control ciudadano de la gestión pública y satisfacer los derechos políticos conexos (Corte Constitucional, 2007).

Así, por ejemplo, el mayor acceso a la información de la que disponen las diversas administraciones y que tenga una repercusión en sus vidas les ayuda a comprender como y por qué se adoptan determinadas decisiones o

10 Mediante el Documento Conpes 2779 de 1995 el Gobierno Nacional formuló la política pública para el fortalecimiento de la sociedad civil, en el cual se plasma la creación de un espacio de asesoría y seguimiento de la política de participación ciudadana.(Departamento Nacional de Planeación, 1995).

11 "Colombia es un Estado social de derecho, organizado en forma de República unitaria, descentralizada, con autonomía de sus entidades territoriales, democrática, participativa y pluralista, fundada en el respeto de la dignidad humana, en el trabajo y la solidaridad de las personas que la integran y en la prevalencia del interés general" (Constitución Política de Colombia, 1991: Art. $1^{\circ}$. como se gastan los impuestos, lo que refuerza su grado de confianza en las actuaciones públicas. Se trata, por tanto, de un paso adelante hacia una Administración más transparente, responsable y abierta que contribuye a reforzar la democracia. Además, una mayor transparencia sirve de ayuda en la lucha contra la corrupción y el fraude en el que pudiera incurrir la Administración.

La rendición de cuentas en el Estado colombiano más que un proceso de reflexión y diálogo entre la sociedad civil y la Administración, se ha convertido en un instrumento necesario para evitar que se oculte información valiosa que debe redundar en el mejoramiento de la calidad de la democracia, al respecto en el Documento Conpes 3294 de 2004 (Departamento Nacional de Planeación) consignó el siguiente diagnóstico:

...Hasta el momento se desconoce si el uso de los recursos de las transferencias por parte de los departamentos y municipios, está afectando positivamente la salud, la nutrición o la escolaridad de la población en qué medida. Esto se debe primordialmente, a la precariedad de la información disponible, al débil control social en las regiones y a la ausencia de evaluaciones de impacto de éstos recursos sobre los beneficiarios y las regiones.

De lo anterior se puede observar la evidente debilidad institucional del Estado colombiano para generar, analizar, procesar y difundir la información pública, dejando un amplio margen para que la corrupción se apodere de esos espacios en donde la gestión pública es ineficiente, razón por la cual la participación ciudadana y la actividad de la sociedad civil juegan un papel determinante en la consolidación de la democracia y fortalecimiento de la administración pública.

En la XI Conferencia Iberoamericana de Ministros de Administración Pública y Reforma del Estado celebrada en Lisboa, la Asamblea acogió el concepto de "derecho a la participación ciudadana en la gestión pública (CLAD, 2009), es decir, el derecho de todo ciudadano iberoamericano de participar colectiva e individualmente en la gestión pública, basados en los principios de corresponsabilidad social y democratización de la gestión pública.

La participación ciudadana en la gestión pública ${ }^{12}$ es necesaria para fortalecer los procesos de modernización del

12 Entiéndase como "el proceso de construcción social de las políticas públicas, que conforme al interés general de la sociedad democrática, canaliza da respuesta o amplía los derechos económicos, sociales, culturales, políticos $y$ civiles de las personas, y los derechos de las organizaciones o grupos en que se integran, así como los de las comunidades y pueblos indígenas". (CLAD, 2009). 
Estado que están orientados a elevar la capacidad de gestión y así recuperar la legitimidad y credibilidad de las instituciones. Es por eso que la Constitución Política de 1991 estableció los principios de democracia participativa, soberanía popular y el derecho de los ciudadanos a conformar, ejercer y controlar el poder público en el Esta$\mathrm{do}^{13}$ colombiano.

Respecto del derecho de acceso a la información pública por parte de los ciudadanos, la Corte Constitucional ha señalado la obligación de las distintas dependencias de la Administración Pública de proporcionar la información necesaria para el adecuado ejercicio del control ciudadano, precisando que "(...) en una democracia participativa

...El derecho a acceder a la información (artículo 20, C.P.) constituye un instrumento indispensable para el ejercicio del derecho político fundamental a participar en "el control del poder político" (artículo 40, C.P.), de lo cual depende la efectividad de principio de responsabilidad política (artículo 133, C.P.), así como la materialización del principio de publicidad que rige la función administrativa (artículo 209, C.P. (...)" (Corte Constitucional, 2002).

Ahora bien, es claro que la participación ciudadana ${ }^{14}$ en la gestión pública y el acceso a una información veraz y oportuna de la Administración por parte de los ciudadanos son pilares esenciales dentro del diálogo que los procesos de rendición de cuentas generan, no obstante dicho diálogo sería inútil si la transparencia no se presenta como elemento integrador entre estos dos.

De acuerdo con lo anterior, la transparencia surge como un medio -un poderoso medio- para propender a la democratización e, incluso, a la eficiencia de la gestión y de las políticas públicas. Lo primero, la democracia, porque posibilita que la ciudadanía o sus agentes sociales aporten a la formación de opinión pública sobre decisiones públicas pasadas y futuras. (Cunill, 2006) Lo segundo, la eficiencia, porque la publicidad sobre los actos y resul-

13 En el preámbulo y en varios artículos de Constitución Política se hace alusión a la adopción del Estado Social de Derecho y la democracia como el régimen político de nuestra organización estatal, lo que no solo tiene un efecto político, sino también social, económico, ecológico y cultural. Por ello, se reconoce a la democracia en nuestro ordenamiento constitucional como de vocación universal y expansiva, alrededor del pluralismo y la participación, como condiciones de su eficacia.

14 El artículo 103 de la Constitución Política de 1991 establece como un deber del Estado el contribuir a "la organización, promoción y capacitación de las asociaciones profesionales, cívicas, sindicales, comunitarias, juveniles, benéficas o de utilidad común no gubernamentales, sin detrimento de su autonomía con el objeto de que constituyan mecanismos democráticos de representación en las diferentes instancias de participación, concertación, control y vigilancia de la gestión pública que se establezcan". tados activa la competencia por la aprobación social y la competencia de ideas.

En este sentido, la rendición de cuentas es un instrumento que garantiza en cierta medida la transparencia en la Administración Pública. No en vano, la Convención de Naciones Unidas contra la Corrupción celebrada en Nueva York (2004) en su artículo $5^{\circ 15}$ definió la rendición de cuentas dentro de las "políticas y prácticas de prevención de la corrupción".

La Corporación Transparencia por Colombia en un reciente informe (2009) indica que los índices de corrupción en la Administración Pública ascienden a un $69.5 \%$ ubicándose en un lugar de riesgo medio para la corrupción (Colombia C. T., 2009), sin embargo las mayores amenazas identificadas por el Índice de Transparencia Nacional en la gestión pública se encuentran en la publicidad de la contratación estatal, la calidad de las audiencias públicas de rendición de cuentas, la selección por mérito y la evaluación de los servidores públicos.

La falta de participación de la sociedad en el conocimiento de la información pública que los afectaría directamente impide el desarrollo amplio de sociedades democráticas exacerbando posibles conductas corruptas dentro de la gestión gubernamental y promoviendo políticas de intolerancia y discriminación. La inclusión de todos los sectores de la sociedad en los procesos de comunicación, decisión y desarrollo es fundamental para que sus necesidades, opiniones e intereses sean contemplados en el diseño de políticas y en la toma de decisiones (Comisión Interamericana de Derechos Humanos, 2001).

No obstante a que la Ley 1151 de 2007 por la cual se adoptó el Plan Nacional de Desarrollo 2006-2010 estableció dentro de sus objetivos la rendición de cuentas en el marco de la contrucción de "un mejor Estado al servicio del ciudadano en el cual se consoliden el modelo democrático y los mecanismos de participación, se reestructure y fortalezca la administración de justicia, se posibilite la intervención del Estado a través de funciones de planeación, promoción, regulación, control y participación en actividades empresariales y en un marco de eficiencia y transparencia. Además, se buscará mejorar la calidad y eficacia del ejercicio de control fiscal para la correcta inversión y manejo de recursos del Estado", lo cierto es que los niveles de desempeño de la rendición de cuentas en el sector público colombiano son realmente deficientes, así lo indica-

\footnotetext{
15 "Cada Estado Parte de conformidad con los principios fundamentales de su ordenamiento jurídico, formulará y aplicará o mantendrá en vigor políticas coordinadas y eficaces contra la corrupción que promuevan la participación de la sociedad y reflejen los principios del imperio de la ley, la debida gestión de los asuntos públicos y los bienes públicos, la integridad, la transparencia y la obligación de rendir cuentas" (ONU, 2004).
} 
ba el Índice de Transparencia Nacional 2007-2008 que la puntuaba con un promedio de rendimiento de un $57,7 \%$, en riesgo medio.

Los resultados del Informe 2007-2008 del Índice de Transparencia Nacional elaborado por la Corporación Transparencia por Colombia, concluyen que en el tema de rendición de cuentas si bien las entidades realizan cada vez más audiencias públicas con éste propósito, siguen siendo escasos sobre información clave en gestión -presupuesto, contratación, gestión del empleo, entre otras- al tiempo que se evalúan muy poco.

En definitiva la rendición de cuentas no solamente es un componente del buen gobierno y la gestión pública, sino que se ha convertido en una estrategia central en la construción de un nuevo Contrato Social en Colombia y en la lucha contra la corrupción.

\section{La política de rendición de cuentas social en Colombia: modernización del estado y recuperación de la confianza del ciudadano en la administración pública}

La accountability horizontal provee un importante vínculo con la accountability vertical. Tal como fue concebido en Atenas, si los ciudadanos son la fuente de autoridad del poder político ejercido sobre ellos, entonces tienen el derecho de ser informados de las decisiones de las autoridades democráticas deben ser públicas (O'Donnell, 2007), en el doble sentido de que las razones y contenido de esas decisiones son especificados en normas legales que también están públicamente disponibles, en este sentido la accountability vertical es determinante.

La accountability societal es un mecanismo no electoral, pero vertical, de control de autoridades políticas que descansa en las acciones de un múltiple conjunto de asociaciones de ciudadanos y de movimientos y sobre los medios, acción que tiene como objetivo el exponer los errores gubernamentales, trayendo nuevas cuestiones a la agenda pública, o de activar el funcionamiento de agencias horizontales. Emplea herramientas institucionales y no institucionales. La activación de demandas legales o reclamos ante agencias de control es un ejemplo de recursos institucionales; las movilizaciones sociales y exposés ilustran algo de los no institucionales, [cuya efectividad] se basa en sanciones simbólicas (Smulovitz y Peruzzotti, 2004 citados por O'Donnell, 2007).

Algunos autores sostienen que la accountability vertical electoral es insuficiente pues no permite medir con precisión la calidad democrática de un sistema, toda vez que el control social solo puede efectuarse ante el gobernante cada cierto tiempo y repercute solo en la reelección o no de éste. Sin embargo, Peruzzotti y Smulovitz son enfáticos en sostener que efectivamente se necesita de un accountability vertical social que les permita a los ciudadanos un diálogo directo con las instituciones.

El control del ciudadano sobre los políticos es en el mejor de los casos sumamente imperfecto en la mayoría de las democracias. Las elecciones no son un mecanismo suficiente para asegurar que los gobiernos harán todo lo posible para maximizar el bienestar de los ciudadanos(as) [...] Pero si las responsabilidades estuvieren claramente asignadas, si los malos gobiernos pueden ser castigados y los buenos pueden ser electos, si los votantes están bien informados acerca de las relaciones entre los políticos e intereses especiales, y si el comportamiento egoísta (rentseeking) de los políticos es bien supervisado, aún así las elecciones no son un instrumento suficiente de control sobre los políticos. Los gobiernos toman miles de decisiones que afectan el bienestar individual; los ciudadanos (as) tienen sólo un instrumento para controlar estas decisiones: el voto. No es posible controlar mil objetivos con un solo instrumento ${ }^{16}$. (Manin, Stokes y Przeworski (1998:50) citado por O'Donnell, 2007).

En Colombia hacía mucho tiempo era necesario una política de rendición de cuentas vertical social, debido a que los diagnósticos sobre el estado de la Administración Pública indicaban que es aquella en la cual hay mayor necesidad y también mayor oportunidad de incidir a través de lineamientos de política. En ese sentido, el Departamento Nacional de Planeación sostuvo que la iniciativa de presentar esta política obedecía a la necesidad de mejorar la transparencia del sector público colombiano y fortalecer la generación de información, los controles sobre el desempeño y la gestión de las entidades públicas, la responsabilidad de las autoridades públicas por la gestión realizada ante los ciudadanos y la petición de cuentas en ejercicio del control social (Departamento Nacional de Planeación, 2010).

Los principales ejes problemáticos que se planteaban para la construcción de una Política Pública sobre Rendición de Cuentas Social se traducían en el manejo de la información que se entregaba a los ciudadanos, pues era incompresible, incompleta o insuficiente para satisfacer sus requerimientos. Anótese además que la información disponible

16 El artículo 133 constitucional consagra una forma de accountability horizontal propia del Poder Legislativo, a saber:"Los miembros de cuerpos colegiados de elección directa representan al pueblo, y deberán actuar consultando la justicia y el bien común. El voto de sus miembros será nominal y público, excepto en los casos que determine la ley. El elegido es responsable políticamente ante la sociedad y frente a sus electores del cumplimiento de las obligaciones propias de su investidura" (Subrayado y negrillas fuera de texto). 
se encontraba desactualizada y cuando se entregaba no se hacía dentro de su oportunidad, razón por la cual se activaba innecesariamente a la administración de justicia para obligar a la Administración a cumplir con su deber.

Uno de los ejes problemáticos que se evidenciaron en un estudio adelantado por la Corporación Transparencia por Colombia (2009), demostró las enormes limitaciones y barreras que se ceñían sobre los ciudadanos para acceder a la información; según esos datos el promedio de publicación en línea de los documentos públicos es de 30\% y tan solo 4 entidades nacionales alcanzan a reportar un $80 \%$ de la información pública en línea (Planeación, 2010).

En lo que respecta a la realización de audiencias públicas de rendición de cuentas, el Departamnento Nacional de Planeación informó que el 75\% de las entidades públicas las efectúan, sin embargo la calidad del diálogo es bastante deficiente, en parte por la estructura con la que se organiza al punto de convertirse en un proceso unidireccional y no bidireccional, hasta el el punto que el número de asistentes alcanza tan solo el $2 \%$ de la población mayor de edad. Lo anterior reafirma las tesis de García-Iragorri (2008) respecto a la comprensión del rol de la sociedad civil en el fortalecimiento de la democracia, pues es necesario ir más allá de la medición de su densidad y ocuparse también de la evaluación de la habilidad para formar parte del proceso de decisión. Una sociedad civil densa como la colombiana sólo indica la presencia de un gran número de grupos y asociaciones, pero no es un indicador del nivel de penetración de estos grupos. Esto hace más evidente la paradoja colombiana consistente en que el aumentar el número de grupos disminuye la calidad de la democracia.

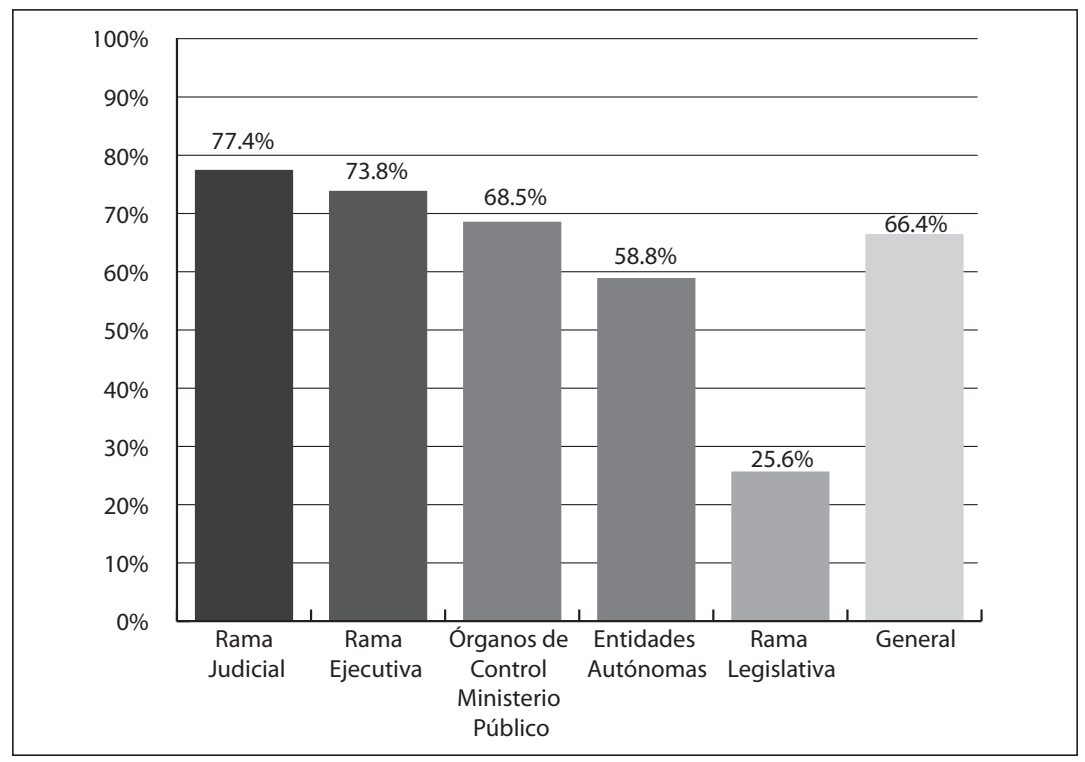

Fuente: Índice de Transparencia Nacional Resultados 2007-2008. Corporación Transparencia por Colombia.

Ilustración 3. Factor Visibilidad. Calificación por Tipo de entidades

El desarrollo de mecanismos de rendición de cuentas social impacta en los niveles de visibilidad de las entidades públicas, otorgándole legitimidad y reconocimiento a las actuaciones de la Administración por parte de los ciudadanos y construyendo un ambiente de confianza y diálogo entre gobierno y sociedad civil.

Los resultados del Índice de Transparencia Nacional para el período 2007-2008, demuestran que las ramas del poder público alcanzan tan solo un $66,4 \%$ de visibilidad en sus actuaciones; lo anterior tiene sus razones en parte al inadecuado reconocimiento del alcance y utlización de la rendición de cuentas social por parte de las entidades y los servidores públicos, los diseños y desarrollos institucionales que no permiten aprovechar los recursos para efectuar la rendición social de cuentas y por evidentes vacíos normativos e institucionales para efectuarla, tal vez, este último el que genera mayor afectación a su adecuado desarrollo.

En Colombia los incentivos para que las entidades públicas realicen ejercicios de rendición social de cuentas es realmente bajo y el marco normativo que conlleva a su obligatoriedad está muy disperso en múltiples normas, dificultando así su apropiación uso, seguimiento y aplicación. (Planeación, 2010) En efecto los vacíos existentes 
en las normas que regulan la rendición de cuentas en Colombia, brindan a las entidades públicas cierta discrecionalidad que se ve reflejada en la no rendición y en el estancamiento de medidas que fomenten una gestión pública participativa; adicionalmente con la carencia de obligaciones claras de rendición de cuentas frente a los espacios de participación ciudadana y la ausencia de instrumentos jurídicos concretos que asignen poder a la sociedad civil para tener un mayor control sobre las actuaciones de la Administración.

Es claro que existen un sinnúmero de obstáculos para una apropiada implementación de la Política Pública de Rendición de Cuentas en Colombia, entre ellos, la poca pedagogía e información que se maneja en cuanto a la rendición de cuentas social, las pocas posibilidades de que los ciudadanos opinen y retroalimenten a las entidades públicas sobre sus actividades, los espacios restringidos para efectuar los ejercicios de rendición de cuentas social, ademas de las limitaciones para incentivar a los ciudadanos a que pidan cuentas y el desconocimiento de los mecanismos e instancias de control social por parte de la ciudadanía.

Sin embargo, la formulación de una Política Pública de Rendición Social de Cuentas se suma a la consigna contenida en el Plan Nacional de Desarrollo 2006-2010 ${ }^{17}$, es la de construir una Administración Pública al servicio del ciudadano en la consolidación de un Estado eficiente y transparente, en este sentido se plantearon como objetivos:

i. La consolidación de una política activa de servicio al ciudadano, que incorpore la responsabilidad del funcionario frente al público, respeto en la interacción entre la Administración y el ciudadano, el adecuado trámite a las peticiones, quejas y reclamos, la competencia y calidad en la provisión de los servicios y la protección al consumidor y al usuario.

ii. La generación de estrategias tendientes a modificar las percepciones ciudadanas sobre la Administración, referidas a su ineficacia e ineficiencia, arbitrariedad, corrupción, falta de continuidad, clientelismo, despilfarro y mal uso de los servicios públicos. Para trabajar en esta línea, se proyecta la creación de un Sistema Nacional de Servicio al Ciudadano.

Debe tenerse claro que la reforma del Estado no sólo se sustenta en cambios normativos o formales. La percepción de ineficacia e ineficiencia, arbitrariedad, altos niveles de corrupción, falta de continuidad, clientelismo, despilfarro y mal uso de los recursos públicos genera falta de credibilidad, ingobernabilidad y desconfianza.

17 Ver. Congreso de la República de Colombia. Ley 1151 de 2007.
Conseguir esto para por definir procedimientos para la rendición de cuentas de todas las instituciones públicas y por asegurar la continuidad de las políticas de Estado (Colombia, 2005).

Un informe reciente de la Corporación Latinobarómetro demuestra que el grado de confianza de los ciudadanos en la Administración Pública es tan solo de un $34 \%$, un porcentaje escaso que significa la poca credibilidad y legitimidad otorgada por los ciudadanos a sus instituciones. Por eso, el Estado colombiano está comprometido con la recuperación de la confianza de los ciudadanos en la Administración Pública y en su gestión; la toma de decisiones orientadas a fortalecer los canales de interacción entre la sociedad civil y el gobierno así lo indican.

El documento de política nacional "Visión Colombia Segundo Centenario: 2019" que refleja las aspiraciones y expectativas del Estado y la sociedad colombiana a futuro plantea dentro de sus objetivos la "Construcción de una sociedad de ciudadanos libres y responsables" y una de sus estrategias es "profundizar el modelo democrático" y "forjar una cultura ciudadana", se relacionan con la construcción de un "Estado Eficiente al Servicio de los ciudadanos", que tiene entre sus metas las de consolidar un Estado eficiente y transparente y avanzar hacia una sociedad informada, así como el fortalecimineto de los procesos de descentralización. (Colombia, 2005).

El Estado colombiano se propone orientar la gestión pública hacia el logro de resultados a través del fortalecimiento e institucionalización de la evaluación, el seguimiento, y la rendición de cuentas de las políticas y programas del gobierno como una práctica permanente del Estado (Departamento Nacional de Planeación, 2004). Con ello se busca contribuir al desarrollo de tres objetivos centrales:

i) Mejorar la eficacia y el impacto de las políticas, programas e instituciones públicas

ii) Contribuir a mejorar la eficiencia y transparencia en la programación y asignación de los recursos.

iii) Estimular la transparencia en la gestión pública, incorporando de manera activa el control de la ciudadanía.

La Política Pública de Rendición de Cuentas Social está enfocada hacia la difusión de resultados, es decir, a la definición de procesos mediante los cuales el gobierno y las entidades públicas entreguen información de manera continua y consistente a los ciudadanos sobre el seguimiento y evaluación de sus actuaciones. Mediante el documento de política Conpes 2790 de 2004 (Departamento Nacional Planeación), el gobierno nacional ya había adop- 
tado la Política de Gestión Pública orientada a resultados y creó el Sistema Nacional de Seguimiento de la Gestión y Evaluación de Resultados, en el cual planteaba dentro de sus objetivos "establecer un Gobierno para el ciudadano a través de la rendición de cuentas y y uso de las TIC's".

Es una política estatal la búsqueda de mecanismos para adaptar las entidades e instituciones del Estado a la Sociedad de la Información y dentro de sus estrategias conocer que la rendición social de cuentas es solo un instrumento que debe complementarse con la administración electrónica en el sector público, no solamente para la modernización del Estado sino como un gesto evidente de fortalecimiento de la democracia a través de la participación ciudadana, transparencia y acceso a la información.

Este Plan de Acción pone el acento en lo que se va a denominar Administración Electrónica, esto es, el conjunto de medidas que deben adoptar las diversas administraciones para incorporar las nuevas tecnologías a sus actuaciones. Este tipo de tecnologías permiten un acceso y una utilización más sencilla de la información de la que disponen las Administraciones Públicas. De este modo, la Administración Electrónica podría transformar la organización tradicional del sector público y proporcionar a los ciudadanos unos servicios más rápidos y sensibles a sus necesidades. Así mismo, puede aumentar la eficiencia y eficacia de la actividad administrativa (Guillén Caramés, 2005).

Para Peruzzotti (2006), el surgimiento de una política de accountability social indica la emergencia de una saludable y novedosa preocupación por la calidad y desempeño de las instituciones democráticas en la región. En un continente que ha estado caracterizado por el predominio de destructivas formas de politización que dificultaron en el pasado la estabilización y consolidación de regímenes democráticos y abrieron las puertas a todo tipo de experiencias autoritarias, la aparición de una forma de política institucionalizante representa de por sí una significativa novedad.

La Política de Rendición de Cuentas Social parte desde una perspectiva estratégica de incorporación del ciuda- dano como protagonista de los procesos y actuaciones propias de la Administración, es la oportunidad para consolidar un Estado democrático, eficaz y transparente en el mejoramiento de la calidad de la gestión pública generando un espacio que recrea una nueva dinámica de diálogo y de construcción social.

\section{Conclusión}

Como parte de una política de fortalecimiento de la transparencia, eficiencia y eficacia en la Administración Pública, se requiere promover una cultura de la rendición de cuentas de los gobernantes hacia la sociedad civil, no entendiéndose como un ejercicio pasivo de entrega de información y explicaciones al ciudadano, sino como un verdadero momento de interlocución entre la Administración y la ciudadanía.

La democracia trasciende más allá de las elecciones, comprende realmente una interacción permeada por las relaciones de poder que existen entre el gobernante y la sociedad civil. Por eso la Política de Rendición de Cuentas Social planteada por el estado colombiano es un eje determinante en el engranaje de las necesidades y expectativas de los ciudadanos hacia la deliberación y construcción de políticas públicas que orienten el desarrollo de la sociedad y, guarda en su seno las herramientas necesarias para lograr la modernización del Estado a través de una adecuado manejo de la información y el uso de las TIC's en la administración pública.

El reto de un estado democrático está en el de lograr una debida articulación entre los diversos actores sociales y el gobernante, así como la de consolidar espacios de reflexión que redunden en el beneficio colectivo y el mejoramiento de la calidad de vida de los ciudadanos, eso solo es posible en la medida en que el ciudadano sea el verdadero protagonista dentro del Estado más allá de la mera retórica institucional. Solamente en el momento en que se reconozcan las dimensiones del diálogo entre los agentes de la Administración y la sociedad civil podremos hablar de cohesión social y una sociedad incluyente.

\section{Referencias}

Ackerman, J. (2004). Co-Governance for Accountability: Beyond "Exit" and "Voice". (págs. 447-463) Great Britain: Elsevier.

Banco Mundial. (2004). State-Society Synergy for Accountability: Lessons for the World Bank (págs. 13-37). Washington D.C.: The World Bank Publications. 
CLAD. (2008). Carta Iberoamericana de Calidad en la Gestión Pública. San Salvador.

CLAD (2009). Carta Iberoamericana de Participación Ciudadana en la Gestión Pública. Lisboa.

Comisión Interamericana de Derechos Humanos. (2001). Informe de la CIDH para la Libertad de Expresión. Washignton D.C.

Constitución Política de Colombia, 1991.

Corporación Latinobarómetro. (2010). Informe 2009. Santiago de Chile.

Corporación Transparencia por Colombia. (2004). El Control Social a la Administración Pública en Colombia En Cuadernos de Transparencia (8) Bogotá D.C.

Corporación Transparencia por Colombia. (2009) Índice de Transparencia Nacional: Resultados 2007-2008 En Colección de Documentos Observatorio de Integridad (10) Bogotá D.C.

Corporación Transparencia por Colombia. (2010) Informe Anual 2009. Bogotá D.C.

Corte Constitucional. (2002) Sentencia, T-596.

Corte Constitucional (2007) Sentencia, T-491.

Cunill, N. (2006). Espacios Públicos No Estatales. En Isunza E. y Olvera, A., Democratización, Rendición de Cuentas y Sociedad Civil: Participación Ciudadana y Control Social (págs. 177-191). México D.F.: Porrúa.

Departamento Nacional de Planeación. (2003). Conpes 3248. Bogotá D.C.

Departamento Nacional de Planeación. (2004a). Conpes 3294. Bogotá D.C.

Departamento Nacional de Planeación. (2004b). Conpes 2790. Bogotá D.C.

Departamento Nacional de Planeación.(2010). Conpes 3654. Bogotá D.C.

García Iragorri, A. (2008). Sociedad Civil y Estado: Del mito a la realidad. Barranquilla: Ediciones Uninorte.

Gutiérrez-Saxe, M. (2006). Desempeño Nacional y Rendición de Cuentas. En Isunza E. y Olvera A., Democratización, Rendición de Cuentas y Sociedad Civil: Participación Ciudadana y Control Social (págs. 137-156). México D.F.: Porrúa.

Guillén Caramés, J. (2005). La Administración Electrónica En García Mexía, P., Principios de Derecho de Internet (págs. 249250). Valencia, España: Tirant Lo Blanch.

Huntington, S. (1994). La Tercera Ola: La democratización a finales del siglo XX. Barcelona: Paidos.

Isunza, E. y Olvera, A. Rendición de Cuentas: Los fundamentos teóricos de una práctica de la ciudadania. En Ziccardi, Alicia (ccord). Participación Ciudana y Políticas Sociales en el ámbito local. (págs. 335-358). México D.F.: UNAM/INDESOL/COMECSO.

Manin, B., Przeworski, Adam y Stokes, Susan. Democracy, Accountability and Representation. United States: Cambridge University Press.

Nonell, R. (2006). Transparencia y Buen Gobierno: La rendición de cuentas en una sociedad avanzada. Barcelona: Icaria.

O'Donnell, G. (2007). Disonancias: Críticas Democráticas a la Democracia. Buenos Aires: Prometeo.

ONU (2004). Convención de la Organización de las Naciones Unidas contra la Corrupción. New York.

Palacio, M. y Safford, F. (2004). Colombia: País Fragmentado, Sociedad Dividida: Su Historia. Bogotá D.C.: Norma.

Peruzzotti, E. (2006). La política de Accountability Social en América Latina En Isunza, E. y Olvera, A. Democratización, Rendición de Cuentas y Sociedad Civil: participación Ciudadana y Control Social (págs. 245-260). México D.F.: Porrúa.

Presidencia de la República de Colombia. (2005). Visión Colombia Segundo Centenario: 2019. Bogotá D.C. 